\title{
The Ergogenic Potential of Arginine
}

\author{
Bill I Campbell, Paul M. La Bounty, Mike Roberts \\ Exercise and Sport Nutrition Laboratory, Baylor University, Waco, TX. Address correspondence \\ to William_I_Campbell@baylor.edu
}

Received November 9, 2004 /Accepted December 28, 2004/Published (online)

\begin{abstract}
Arginine is a conditionally essential amino acid that is involved in protein synthesis, the detoxification of ammonia, and its conversion to glucose as well as being catabolized to produce energy. In addition to these physiological functions, arginine has been purported to have ergogenic potential. Athletes have taken arginine for three main reasons: 1) its role in the secretion of endogenous growth hormone; 2) its involvement in the synthesis of creatine; 3 ) its role in augmenting nitric oxide. These aspects of arginine supplementation will be discussed as well as a review of clinical investigations involving exercise performance and arginine ingestion. Journal of the International Society of Sports Nutrition. 1(2):35-38, 2004
\end{abstract}

Key Words: sports supplements, sports nutrition, amino acids, nitric oxide

\section{INTRODUCTION}

Arginine is a basic amino acid and is classified as a conditionally essential amino acid. The typical dietary intake of arginine is 3.5 to 5 grams daily ${ }^{1}$. One of the main functions of arginine is its participation in protein synthesis ${ }^{2,3}$. Also, arginine is involved in a number of other roles in the body such as the detoxification of ammonia formed during the nitrogen catabolism of amino acids via the formation of urea ${ }^{1}$; its potential to be converted to glucose (hence its classification as a glycogenic amino acid); and its ability to be catabolized to produce energy ${ }^{1}$. Arginine is utilized by a number of metabolic pathways that produce a variety of biologically active compounds such as nitric oxide, creatine, agmatine, glutamate, polyamines, ornithine, and citrulline ${ }^{2,3}$.

In addition to these physiological functions, arginine has been purported to have ergogenic potential. Athletes have taken arginine for three main reasons: 1) its role in the secretion of endogenous growth hormone ${ }^{4}$;2) its involvement in the synthesis of creatine; 3 ) its role in augmenting nitric oxide. The focus of this review will be to investigate these various ergogenic possibilities and to examine the investigations that have looked at arginine supplementation and exercise performance.

\section{ARGININE AND GROWTH HORMONE}

It is well documented that the infusion of arginine stimulated growth hormone secretion from the anterior pituitary ${ }^{5-7}$. This increase in growth hormone secretion from arginine infusion has been attributed to the suppression of endogenous somatostatin secretion ${ }^{8}$. The amounts of arginine infused to elicit the growth hormone response ranged from 12 grams to 30 grams. The clinical investigations of oral consumption of arginine and its impact on growth hormone release are not in agreement. When arginine $(1.2 \mathrm{~g})$ was ingested along with the amino acid lysine $(1.2 \mathrm{~g})$ in young 
males, peak plasma growth hormone concentrations increased 8 -fold at 90 minutes post-ingestion ${ }^{9}$. However, when arginine and lysine were ingested alone at the same doses, there was no corresponding increase in plasma growth hormone. Suminiski and associates ${ }^{10}$ reported that the ingestion of arginine $(1.5 \mathrm{~g})$ and lysine $(1.5 \mathrm{~g})$ resulted in a 2.7 -fold increase in plasma growth hormone concentrations in resistance trained males. Colombani et al. ${ }^{11}$ supplemented marathon runners with $15 \mathrm{~g}$ arginine aspartate for 14 days before a marathon run. On the day of the marathon, blood samples were taken shortly before the run, after $31 \mathrm{~km}$, at the end of the run, and after a recovery period of two hours. The researchers found that growth hormone concentrations were elevated during a marathon run to a greater degree than exercise would elicit alone.

Other studies using either resistance trained or physically active individuals showed no increases in plasma growth hormone concentrations following arginine supplementation. When resistance trained males consumed approximately 8 grams of arginine daily for 17 days there was no associated changes in growth hormone concentrations ${ }^{12}$. Similarly, Lambert et al. ${ }^{13}$ gave male bodybuilders $1.2 \mathrm{~g}$ of arginine and $1.2 \mathrm{~g}$ of lysine. This supplementation did not induce a statistically significant increase in serum growth hormone concentrations over a 3 hour period. In a recent review, Chromiak and Antonio ${ }^{4}$ highlighted several factors that appear to modify the growth hormone response to amino acid administration. These include training status, age, sex, diet, and time since last meal. Also, the growth hormone response to amino acid ingestion may be reduced in exercise-trained individuals ${ }^{4}$. These authors concluded that the practice of consuming specific amino acids, including arginine, during or after exercise does not appear to be effective ${ }^{4}$.

\section{ARGININE AND CREATINE}

Another possible ergogenic potential of arginine is its role in the synthesis of creatine. Arginine, glycine, and methionine are the three amino acids involved in the synthesis of creatine. Creatine has been shown to increase muscular strength ${ }^{14}$ and muscle fiber size ${ }^{15}$. In addition, creatine supplementation enhances performance in swimming, all out cycling, sprinting, repeated jumping, and resistance training ${ }^{16}$. It is worth noting that these improvements in muscle function and exercise performance were the result of creatine supplementation. A question to be asked is whether an increase in dietary or supplemental arginine results in an increase in creatine stores to the levels observed where there was performance enhancement. Do to the fact that the rate limiting step in the synthesis of creatine from arginine and glycine is the formation of guanidinoacetate by the enzyme arginine:glycine amidino-transferase (AGAT) ${ }^{17}$ and not arginine concentration; furthered by the fact that dietary creatine ingestion downregulates AGAT ${ }^{18}$, it is unlikely that additional arginine ingestion leads to increases in creatine concentration needed to improve performance. Rather, the most likely method of increasing performance from increases in creatine stores is from supplemental creatine or increasing dietary creatine.

\section{ARGININE AND NITRIC OXIDE}

Arginine is a precursor of the cell-signaling molecule nitric oxide (NO). $\mathrm{NO}$ acts as a signaling molecule to facilitate the dilation of blood vessels and decrease vascular resistance. NO is synthesized from arginine under the enzymatic control of nitric oxide synthase (NOS). There are three NOS isoforms, endothelial cell NOS (eNOS), neuronal NOS (nNOS), and inducible NOS (iNOS). Skeletal muscle expresses all three forms of NOS, with nNOS predominating. Muscle functions regulated by NO or related molecules include force production 
(excitation-contraction coupling), autoregulation of blood flow, myocyte differentiation, respiration, and glucose homeostasis ${ }^{19}$. Contractile activity greatly increases NO production in the muscle, and this is likely due to elevated intracellular calcium ${ }^{20}$. One of the main effects of NO on skeletal muscle metabolism is to increase the delivery and uptake of fuel substrates via its vasodilating effects ${ }^{21}$. Even though arginine augments nitric oxide production, there is still no clear evidence that this synthesis of nitric oxide results in improvements in exercise performance in healthy individuals.

\section{ARGININE AND EXERCISE PERFORMANCE}

With all of the aforementioned effects that arginine possesses in relation to ergogenic potential, it would seem plausible that supplementing with arginine would improve exercise performance and body composition. There is scant evidence that this is the case in humans, and the available data is conflicting. When male weight trainers on a hypocaloric diet ingested approximately 8 grams of arginine daily, there were no positive influences on muscle function (biceps/quadriceps isokinetic assessments) or body composition ${ }^{12}$. Conversely, when untrained males were given 3 grams of arginine daily for 15 days and underwent a test retest protocol evaluating resistance to muscular fatigue (by quadriceps isokinetic dynamometry), there was a significant resistance to muscular fatigue ${ }^{22}$. Unfortunately, the investigators did not utilize a double-blinded protocol nor was there a placebo or control group.

In addition to the studies conducted on healthy subjects, there are also several studies investigating the effects of oral arginine supplementation in subjects with cardiovascular issues ${ }^{23-25}$. Subjects with congestive heart failure ingested 9 grams of arginine daily for 7 days. At the end of the supplementation period, the authors concluded that in patients with chronic stable congestive heart failure, supplementation with a moderate dose of arginine resulted in a prolonged exercise duration as compared to placebo ${ }^{23}$. In patients with healed myocardial infarction, investigators ${ }^{24}$ supplemented the participants with 6 grams of arginine for 3 days. After only 3 days of such supplementation, the authors concluded that oral arginine supplementation had a beneficial effect on exercise capacity in patients with stable angina.

Nagaya, et al. ${ }^{25}$ studied the effects of oral supplementation of arginine on exercise capacity in patients with pulmonary hypertension. Cardiorespiratory exercise tests were performed to measure peak oxygen consumption. The supplementation protocol required that each treated subject consume $1.5 \mathrm{~g}$ of arginine per $10 \mathrm{~kg}$ of body weight per day for 7 days. A significant increase in peak oxygen consumption was observed. A possible mechanism to describe this increase in performance is the role that arginine has in augmenting nitric oxide. An increase in nitric oxide bioavailability results in coronary vessel vasodilatation and flow, which in turn may positively influence coronary perfusion.

\section{CONCLUSION}

Arginine's involvement as a precursor of creatine and its potential to increase endogenous growth hormone makes it a popular supplement among those who wish to improve their physical performance. The choice to supplement with arginine is also based on sound physiologic theory. However, there is currently little scientific evidence available to support such claims promoting and increase in functional capacity in healthy, athletic participants. Among those with cardiovascular issues (congestive heart failure, healed myocardial infarction, and pulmonary hypertension) there does seem to be some rational for ingesting arginine (3-9g/day) for an improvement in physical performance. 
These improvements may be accounted for via arginine's role as a precursor to nitric oxide. More research is needed to evaluate the role of arginine supplementation on exercise performance and training adaptations in healthy and diseased populations before any conclusions can be drawn.

\section{REFERENCES}

1. PDR for Nutritional Supplements, Montvale, NJ: Thompson PDR.; 2001

2. Tong BC, Barbul, A. Cellular and physiological effects of arginine. Mini Reviews in Medicinal Chemistry 2004;4(8):823-32.

3. Wu G, Morris SM. Arginine metabolism: nitric oxide and beyond. Biochem. J. 1998;336:1-17.

4. Chromiak JA, Antonio J. Use of amino acids as growth hormone-releasing agents by athletes. Nutrition 2002;18(7/8):657-661.

5. Merimee TJ, Rabinowitz D, Riggs L, et al. Plasma growth hormone after arginine infusion. Clinical experiences. N Engl J Med 1967;276(8):434-9.

6. Merimee TJ, Rabinowitz D, Fineberg SE. Arginine-initiated release of human growth hormone. Factors modifying the response in normal man. N Engl J Med 1969;280(26):1434-8.

7. Hembree WC, Ross GT. Arginine infusion and growth-hormone secretion. Lancet 1969;1(7584):52.

8. Alba-Roth J, Muller OA, Schopohl J, et al. Arginine stimulates growth hormone secretion by suppressing endogenous somatostatin secretion. J Clin Endocrinol Metab 1988;67(6):1186-9.

9. Isidori A, Lo Monaco A, Cappa M. A study of growth hormone release in man after oral administration of amino acids. Curr Med Res Opin 1981;7(7):475-81.

10. Suminiski RR, Robertson RJ, Goss FL, et al. Acute effect of amino acid ingestion and resistance exercise on plasma growth hormone concentration in young men. Int J Sport Nutr 1997;7:48-60.

11. Colombani PC, Bitzi R, Frey-Rindova P, Frey W, et al. Chronic arginine aspartate supplementation in runners reduces total plasma amino acid level at rest and during a marathon run. Eur J Nutr 1999;38:263-70.

12. Walberg-Rankin J, Hawkins C, et al. The effect of oral arginine during energy restriction in male weight trainers. J Strength Cond Res 1994;8(3):170-7.

13. Lambert MI, Hefer JA, Millar RP, Macfarlane PW. Failure of commercial oral amino acid supplements to increase serum growth hormone concentrations in male bodybuilders. Int J Sport Nutr 1993;3:298.

14. Vandenberghe k, Goris M, Van Hecke P, Van Leemputte M, et al. Long-term creatine intake is beneficial to muscle performance and pharmacokinetic considerations. J Appl Physiol 1997;83:2055-2063.

15. Volek JS, Duncan ND, Mazzetti SA, Putukian M. Performance and muscle fiber adaptations to creatine supplementation and heavy resistance training. Med Sci Sports Exerc 1999;31:1147-1156.

16. Juhn MS, Tarnopolsky M. Oral creatine supplementation and athletic performance: A critical review. Clin J Sport Med 1998;8:286-297.

17. Walker JB. Creatine: biosynthesis, regulation, and function. Adv Enzymol Relat Areas Mol Biol 1979;50:177-242.

18. Stead LM, Au KP, Jacobs RL, Brosnan ME, et al. Methylation demand and homocysteine metabolism: effects of dietary provision of creatine and guanidineacetate. Am J Physiol 2001;281:E1095-E1100.

19. Stamler JS, Meissner G. Physiology of nitric oxide in skeletal muscle. Physiol Rev 2001;81(1):209-237.

20. Kobzik L, Reid MB, Bredt DS, Stamler JS. Nitric-oxide in skeletal muscle. Nature 1994;372(6506):546-548.

21. Wolin MS, Hintze TH, Shen W, Hohazzabh KM, et al. Involvement of reactive oxygen and nitrogen species in signaling mechanisms that control tissue respiration in muscle. Biochem Sos Trans 1997;25(3):934-939.

22. Santos RS, Pacheco MTT, Martins RABL, Villaverde AB, et al. Study of the effect of oral administration of L-arginine on muscular performance in healthy volunteers: an isokinetic study. Isokinetics and Exercise Science 2002;10(3):153-158.

23. Bednarz B, Jaxa-Chamiec T, Gebalska J, Herba K, et al. L-arginine supplementation prolongs duration of exercise in congestive heart failure. Polish Heart Journal 2004;60(4):348-353

24. Ceremuzynski L, Chamiec T, Herbaczynska-Cedro K. Effect of supplemental oral L-arginine on exercise capacity in patients with stable angina pectoris. Am J Cardiol 1997;80(3):331-333.

25. Nagaya N, Uematsu M, Oya H, Sato N, et al. Short-term oral administration of L-arginine improves hemodynamics and exercise capacity in patients with precapillary pulmonary hypertension. Am J Respir Crit Care Med 2001;163:887-891. 